\title{
Numerical Analysis of Reaction Degradation for Three- dimensional Coke Pore Structure
}

\author{
Yui NUMAZAWA, ${ }^{11}$ Daisuke IGAWA, ${ }^{1)}$ Shohei MATSUO, ${ }^{11}$ Yasuhiro SAITO, ${ }^{1) *}$ Yohsuke MATSUSHITA, ${ }^{1)}$ \\ Hideyuki AOKI, ${ }^{1)}$ Takahiro SHISHIDO ${ }^{2)}$ and Noriyuki OKUYAMA ${ }^{2)}$
}

1) Department of Chemical Engineering, Graduate School of Engineering, Tohoku University, 6-6-07 Aoba, Aramaki, Aoba-ku, Sendai, Miyagi, 980-8579 Japan.

2) Kobe Steel, LTD., 2-3-1 Shinhama, Arima-cho, Takasago, Hyogo, 676-8670 Japan.

(Received on February 26, 2018; accepted on April 23, 2018)

\begin{abstract}
In order to investigate coke degradation behavior due to $\mathrm{CO}_{2}$ gasification reaction in the blast furnace, mass transfer analyses with the reaction and stress analyses for coke considering its structure after the reaction were performed. Using the finite element method, $\mathrm{CO}_{2}$ gas diffusion in a coke lump and consumption of coke matrices owing to the gasification reaction were considered for the coke model in which the actual coke structure was reproduced. The rate-controlling step was also evaluated calculating the Thiele modulus and the effectiveness factor of catalyst obtained from $\mathrm{CO}_{2}$ concentration distribution in a coke lump. Further, stress analyses assuming a uniaxial tensile test were carried out for the coke model after $\mathrm{CO}_{2}$ gasification reaction, and the effect of the gasification reaction on a stress state in a coke lump was investigated. As a result, the reaction progressed mainly in the vicinity of the external surface with reaction temperature of $1673 \mathrm{~K}$ while it did uniformly in the whole coke lump with 1273 and $1473 \mathrm{~K}$. Thus, the rate-controlling step shifted from the reaction-controlling step to the diffusion-controlling step with an increase in a reaction temperature, and the Thiele modulus and the effectiveness factor of catalyst also showed the same trend. From the stress analysis, coke strength decreased uniformly in the whole coke lump in case of the reaction-controlling step whereas it did mainly in the vicinity of the external surface in case of diffusion-controlling step.
\end{abstract}

KEY WORDS: ironmaking; coke degradation behavior; coke strength; gasification; controlling step.

\section{Introduction}

Coke plays an important role in a reducing agent as well as a spacer to keep permeability in the blast furnace. The role as a spacer is especially important for its efficient operation, and coke strength is desired to be high. Coke strength is known to correlate with coke pore structure, ${ }^{1,2)}$ and it decreases with an increase in coke porosity. ${ }^{3)}$ Also, it decreases with progress in reaction because coke matrices are consumed, and the effect of the solution loss reaction is significant. ${ }^{4}$ A decrease in coke strength in the dropping zone and in the raceway on the bottom of the blast furnace causes coke fracture and pulverization. Since the pulverized coke moves and accumulates in the center of the blast furnace and prevents stable operation, coke strength after reaction is also important. Therefore, the effect of coke reactivity and temperature history on coke strength has been investigated. Nishi et al. ${ }^{5)}$ performed experiments of $\mathrm{CO}_{2}$ gasification reaction under elevated temperature conditions and evaluated coke strength after reaction using an I-type drum tester. As a result, they indicated that the amount of the consumed coke affected a decrease in coke strength because the reaction progressed in the whole coke lump

* Corresponding author: E-mail: saito@tranpo.che.tohoku.ac.jp DOI: http://dx.doi.org/10.2355/isijinternational.ISIJINT-2018-144 when reaction temperature was below $1300^{\circ} \mathrm{C}$. In contrast, they suggested that the amount had little influence on coke strength because reaction progressed on the surface of coke when reaction temperature was $1300-1500^{\circ} \mathrm{C}$. Further, Kawakami et al. $\left.{ }^{6}\right)$ carried out experiments of $\mathrm{CO}_{2}$ gasification reaction for spherical coke samples with reaction temperatures of 1273 and $1573 \mathrm{~K}$ and reported that the porous reaction layer was formed near the surface of the sample. Kamijo et al. ${ }^{7)}$ showed that a decrease in diameter was smaller for the coke with high reactivity than for that with low reactivity because the region where coke strength decreased was limited in the vicinity of the surface. The above experiments indicated that the rate-controlling step was different according to reaction temperature and the porous distribution in coke was also different. Moreover, although the coke pore structure and the stress distribution in a coke lump loaded would change with progress in the reaction, it is difficult to precisely understand stress state in a coke lump in experiments. Hayashizaki et al. ${ }^{8)}$ observed the polished surface of coke, developed the two-dimensional coke model considering the internal structure in coke on the basis of the image-based modeling from the observation, and performed the stress analysis using the finite element method. They reported that stress on coke inside increased due to a decrease in wall thickness of micrometer-sized pores and in linking of matrices. Hiraki et al. ${ }^{9)}$ visualized 
the internal structure of coke using the X-ray CT (computed tomography), constructed the coke model with consideration of the pore structure in the three-dimensional coke, and numerically analyzed the stress distribution in it using the finite element method. They argued the difference in the stress distributions in the two- and three-dimensional models and the importance of the three-dimensional analysis. Tsafnat et al. ${ }^{10)}$ imaged the coke samples before and after a compression test using the X-ray CT, generated the finite element mesh of the images, and conducted numerical simulation for the three-dimensional coke model assuming the compression test. They successfully demonstrated the region where von Mises stress was concentrated in a coke lump corresponds to the one where the crack generated in the experiment. Lomas et al. ${ }^{11)}$ also imaged coke with the highresolution X-ray CT and performed stress analysis for the three-dimensional finite element mesh developed. Numerical solution successfully predicted the concentrated stress at the position where crack formed in the experiment. As is mentioned above, coke has been imaged using the X-ray $\mathrm{CT}$, and stress analysis has been performed for the finite element mesh in which the three-dimensional coke structured was directly reproduced. In the blast furnace, since coke matrices degrade due to reactant gas diffusion and reaction with it, they should be taken into account. Coke produced in the coke oven was investigated, but coke degradation behavior due to reaction has not been investigated except Hayashizaki et al. In addition, although Hayashizaki et al. performed the two-dimensional stress analysis for coke after the reaction, they did not analyze changes in stress state in the three-dimensional coke lump.

In this study, we developed the three-dimensional finite element mesh of the actual coke and analyzed diffusion phenomenon of reactant gas, coke reaction behavior, and stress state in a coke lump. Specifically, coke was imaged by the $\mathrm{X}$-ray CT, and the finite element mesh in which complex coke structure was directly reproduced was generated on the basis of the image-based modeling with the CT images obtained. Using the mesh, diffusion of reactant gas and reaction of coke matrices were numerically analyzed based on the finite element method, and the effect of coke pore structure and reaction temperature on reaction behavior of coke was investigated. In addition, to evaluate the relationship between conversion distribution in a coke lump and coke strength, stress analyses assuming a uniaxial tensile test were also performed for the coke model with the conversion distribution at each reaction temperature obtained in the reaction analysis, and the parts where stress concentrated in a coke lump after the reaction were discussed.

\section{Materials and Methods}

\subsection{Analytical Object}

Caking coal listed in Tables $\mathbf{1}$ and $\mathbf{2}$ was packed in the experimental coke oven of an electric heating system with a width of $420 \mathrm{~mm}$, a height of $400 \mathrm{~mm}$, and a length of $600 \mathrm{~mm}$ and carbonized for $18.5 \mathrm{~h}$ with the same condition in an actual coke oven with flue gas of $1250^{\circ} \mathrm{C}$ to prepare coke samples. Then, cylinder samples of $19 \mathrm{~mm}$ in diameter and $30 \mathrm{~mm}$ in height were obtained by boring the center part of a coke lump. The above sample was imaged using
Table 1. Coking condition.

\begin{tabular}{ccc}
\hline Size $[\mathrm{mm}]$ & Moisture [\%] & Charging density $\left[\mathrm{kg} / \mathrm{m}^{3}\right]$ \\
\hline$<3(85 \%)$ & $6-7$ & 750 \\
\hline
\end{tabular}

Table 2. Property of the samples.

\begin{tabular}{ccc}
\hline $\mathrm{DI}_{15}^{150}$ & Porosity [\%] & MF [ddpm] \\
\hline 82.8 & 46.0 & 1920 \\
\hline
\end{tabular}

where DI presents drum index, and MF presents maximum fluidity

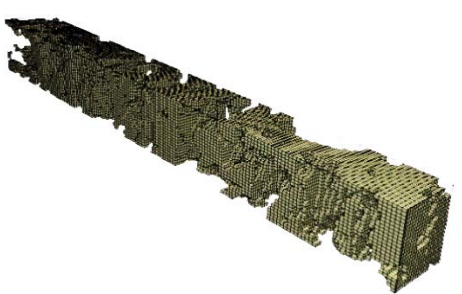

(a) The image of analytical object

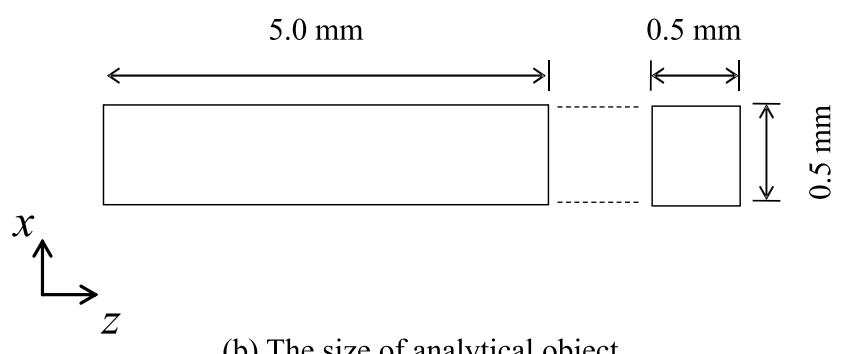

(b) The size of analytical object

Fig. 1. Analytical object. (Online version in color.)

micro X-ray scanner (TOSCANER-32250 $\mu \mathrm{hd}$, Toshiba IT \& Control Systems Corporation, Japan). In the imaging, the tube voltage and current of X-ray were $180 \mathrm{kV}$ and 50 $\mu \mathrm{A}$, respectively, which was the same condition in Hiraki et al. ${ }^{9)}$ In addition, the screen resolution was $20.6 \mu \mathrm{m} / \mathrm{pixel}$, and the slice width was $32 \mu \mathrm{m}$. The X-ray CT images were binarized using the discriminant analysis method, ${ }^{12}$ and the binarized images composed of pores and matrices were obtained. After the voxel image was constructed stacking each sectional image, the analytical object shown in Fig. 1 was generated using the image-based modeling. The analytical object has 89856 hexahedrons with 8 nodes, and its size is $0.5 \mathrm{~mm}$ in width, $0.5 \mathrm{~mm}$ in height, and $5.0 \mathrm{~mm}$ in depth. The size of the analytical object was determined in terms of numerical accuracy and computational load.

\subsection{Numerical Method}

The present study performed mass transfer analyses of gas diffusion with $\mathrm{CO}_{2}$ gasification reaction in a coke lump as well as stress analyses of coke in consideration of its structure before and after reaction based on the finite element method. In particular, the porosity of matrix was given to represent gas diffusion phenomenon in fine pores smaller than the resolution of the X-ray CT. It was assumed that pores in a matrix element did not exist before the reaction, but micro-pores were to be generated in the element by the reaction. In practice, the density of a matrix element was reduced with a decrease in the amount of carbon consumed by the reaction, and the porosity of the matrix element was 
calculated by Eq. (1).

$$
\varepsilon_{\text {elem }}=1-\frac{\rho_{\text {elem }}}{\rho_{\text {true }}}
$$

Here, $\rho_{\text {elem }}$ is the density of a matrix element, $\rho_{\text {true }}$ is the true density of a matrix element, and $\varepsilon_{\text {elem }}$ is porosity of a matrix element, respectively.

\subsubsection{Mass Transfer Analysis with $\mathrm{CO}_{2}$ Gasification Reaction}

Mass transfer of $\mathrm{CO}$ and $\mathrm{CO}_{2}$ was considered assuming that $\mathrm{CO}, \mathrm{CO}_{2}$, and inert gas, $\mathrm{N}_{2}$ existed in a coke lump and $\mathrm{CO}_{2}$ gas reacted with coke matrices. The constant reaction temperature of $1273.15,1473.15$, or $1673.15 \mathrm{~K}$ was given in the whole computational domain. As is shown in Fig. 2(a), the mole fraction of $\mathrm{N}_{2}: \mathrm{CO}_{2}: \mathrm{CO}=0.5: 0.5: 0$ was prescribed at the open boundary, and zero-gradient for mole fractions was applied at the other boundaries. The unsteadystate diffusion equations (Eq. (2)) were solved as governing equations to analyze mass transfer of $\mathrm{CO}$ and $\mathrm{CO}_{2}$.

$$
\frac{\partial}{\partial t}\left(\rho Y_{m}\right)=\frac{\partial}{\partial x_{j}}\left(\rho D_{\mathrm{i}, \mathrm{mix}} \frac{\partial Y_{m}}{\partial x_{j}}\right)+\dot{S}_{m} \text { in } \Omega
$$

Here, $D_{m \text {,mix }}, S_{m}$, and $Y_{m}$ represent diffusion coefficient in the multi-component system, source term, and mass fraction for chemical species $m$, respectively, and $\rho$ is gas density and $\Omega$ represents computational domain. Diffusion coefficient $D_{m \text {,mix }}$ in the gas phase for each chemical species $m$ was estimated by Eq. (3) using binary diffusion coefficients:

$$
D_{\mathrm{i}, \mathrm{mix}}=\frac{1-f_{i}}{\sum_{j=1, i \neq j}^{n} \frac{f_{i}}{D_{i j}}}
$$

where $f_{m}$ is volume fraction for chemical species $m$, and binary diffusion coefficient was evaluated on the basis of the Chapman-Enskog theory as the following equation:

$$
D_{i j}=1.858 \times 10^{-7} \frac{\sqrt{T^{3}\left(\frac{1}{M_{i}}+\frac{1}{M_{j}}\right)}}{\left(\frac{P}{101325}\right) \sigma_{\text {ave }}^{2} \Omega_{\mathrm{D}-\text { ave }}}
$$

where $M$ is molecular weight of gas, $T$ is gas temperature, $P$ is total pressure, $\sigma_{\text {ave }}$ is collision diameter, and $\Omega_{\text {D-ave }}$ is collision integral in the Lennard-Jones potential.

Further, the single pore diffusion model was employed for diffusion coefficient of each chemical species with fine pores in a coke matrix, which could take into account both molecular diffusion and the Knudsen diffusion.

$$
D_{\mathrm{m}}=\frac{\varepsilon}{\tau}\left(\frac{1}{\frac{1}{D_{i, \mathrm{mix}}}+\frac{1}{D_{\mathrm{Kn}}}}\right)
$$

Here, $\varepsilon$ is porosity, $\tau$ is tortuosity, and $D_{\mathrm{Kn}}$ is the Knudsen diffusion coefficient. Tortuosity is known to depend on porosity and was calculated by Eq. (6) proposed by Ronsner and Tandon. ${ }^{13)}$

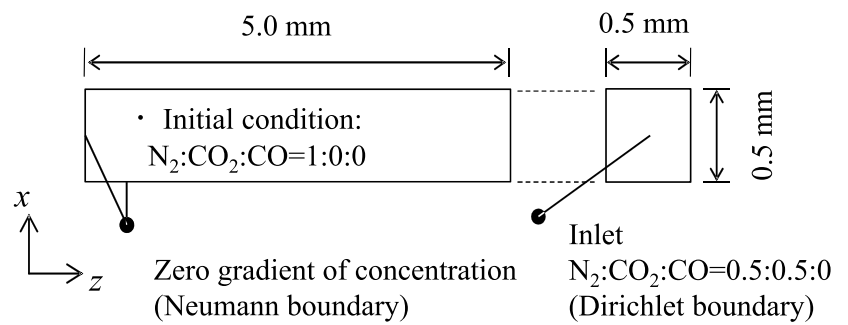

(a) Mass transfer analysis for $\mathrm{CO}_{2}$ and $\mathrm{CO}$.

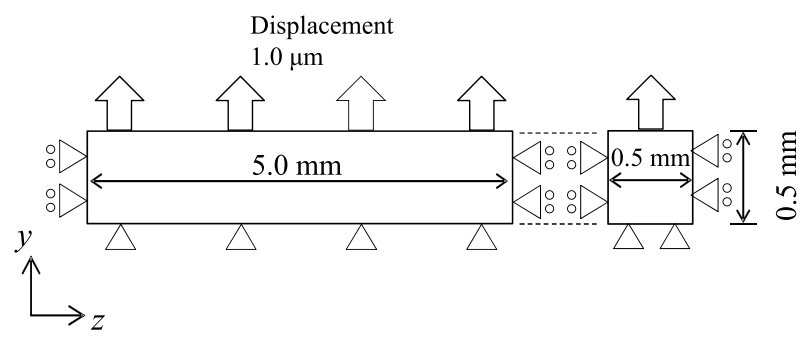

(b) Stress analysis.

Fig. 2. Boundary conditions.

$$
\tau=\varepsilon^{-0.416}
$$

The Knudsen diffusion coefficient depends on temperature and pore diameter and is expressed by Eq. (7):

$$
D_{\mathrm{Kn}}=\left(\frac{2}{3}\right)\left(\frac{8 R T}{\pi M_{i}}\right)^{\frac{1}{2}} r_{e}
$$

where $r_{\mathrm{e}}$ is a pore diameter, $M$ is molecular weight of diffusive gas, $R$ is gas constant. In the source term in Eq. (2), generation of $\mathrm{CO}$ and consumption of $\mathrm{CO}_{2}$ were considered due to $\mathrm{CO}_{2}$ gasification reaction denoted by (R1).

$$
\mathrm{C}+\mathrm{CO}_{2}(\mathrm{~g}) \rightarrow 2 \mathrm{CO}(\mathrm{g})
$$

The reaction rate of $\mathrm{CO}_{2}$ gasification was estimated by reaction rate equation (Eq. (8)) of Kashiwaya and Ishii, ${ }^{14}$ in which reaction rate constants were assumed to differ in crystalline and non-crystalline carbon.

$$
\begin{aligned}
& k_{\mathrm{c}}=\frac{k_{1, \mathrm{c}} P_{\mathrm{CO}_{2}}}{1+k_{2} P_{\mathrm{CO}}+k_{3} P_{\mathrm{CO}_{2}}} \\
& k_{\mathrm{a}}=\frac{k_{1, \mathrm{a}} P_{\mathrm{CO}_{2}}}{1+k_{2} P_{\mathrm{CO}}+k_{3} P_{\mathrm{CO}_{2}}}
\end{aligned}
$$

where $k_{\mathrm{c}}$ and $k_{\mathrm{a}}$ are reaction rate constants of crystalline and non-crystalline carbon, respectively, and $k_{1, \mathrm{c}}, k_{1, \mathrm{a}}, k_{2}$, and $k_{3}$ are reaction rate constants. As is the same with Kashiwaya and Ishii, ${ }^{14)}$ it was assumed that crystallite formation occurred (i.e., $V_{\mathrm{c}}$ increases) at reaction temperature of above $1273 \mathrm{~K}$, and non-crystalline carbon in matrix elements changed into crystalline carbon at reaction temperature of $1673 \mathrm{~K}$. The weight ratio of crystalline carbon, $N_{\mathrm{c}}$ was calculated by Eq. (9).

$$
N_{\mathrm{c}}=\frac{W_{\mathrm{c}, 0}}{W_{0}}=\frac{V_{\mathrm{c}}}{V_{\mathrm{c}, 1673 \mathrm{~K}}}
$$

Here, $V_{\mathrm{c}}$ is volume of crystallite at a temperature. ${ }^{14)}$ Fullyimplicit method was applied for time integral, and AGMG (AGgregation-based algebraic MultiGrid ${ }^{15-18)}$ ) was used for 
solution in system of equations.

\subsubsection{Evaluation of Rate-controlling Step Using Thiele Modulus}

To quantitatively investigate the rate-controlling step of $\mathrm{CO}_{2}$ gasification reaction in a coke lump, it was evaluated using the Thiele modulus, $\varphi$ and the effectiveness factor of catalyst, $\eta$. Assuming the analytical object is a part of a spherical particle, the Thiele modulus is expressed in Eq. (10):

$$
\varphi=\frac{R}{3} \sqrt{\frac{k}{D}}
$$

where $D$ is diffusion coefficient, $k$ is reaction rate constant, $R$ is a particle radius. Gas concentration distribution in the radial direction of a cylinder sample is described by Eq. (11) using the Thiele modulus:

$$
\frac{C}{C_{0}}=\frac{\sinh \left(3 \varphi\left(\frac{r}{R}\right)\right)}{\left(\frac{r}{R}\right) \sinh (3 \varphi)}
$$

where $C$ is the concentration of $\mathrm{CO}_{2}$ gas at the position of $r$ from the external surface of the sample and $C_{0}$ is the one at external surface, $r$ is a distance from the external surface, and $R$ is a particle radius. The effectiveness factor of catalyst, $\eta$ was calculated by Eq. (12) from the Thiele modulus. The effectiveness factor of the catalyst is the ratio of the apparent reaction rate for the ideal one without the effect of intra-particle diffusion, and the rate-controlling step for the radial direction was evaluated by the effectiveness factor of catalyst.

$$
\eta=\frac{1}{\varphi}\left[\frac{1}{\tanh (3 \varphi)}-\frac{1}{3 \varphi}\right]
$$

\subsubsection{Stress Analysis}

Stress analyses were performed for coke before and after $\mathrm{CO}_{2}$ gasification reaction assuming a uniaxial tensile test for the $y$-direction. Boundary conditions are described in Fig. 2(b), in which the bottom side of the computational domain was bounded and the forced displacement of $1.0 \mu \mathrm{m}$ for the $y$-direction was given at the top side. Since coke is a brittle material and its deformation to fracture is slight, the elastic behavior of coke based on Eq. (13) was analyzed as a small displacement elastic problem:

$$
\frac{\partial \sigma_{i j}}{\partial x_{j}}=0
$$

where $\sigma$ represents stress. Poisson's ratios of both pore and matrix were given 0.3 . The coke model was assumed to be a linear elastic body, and the constitutive law of the material is as follows:

$$
\sigma_{i j}=E_{i j k l} \varepsilon_{k l}
$$

where $E$ is the elastic modulus of an element. After gasification reaction, the elastic modulus of matrix was assumed to depend on porosity and calculated by Eq. (15) which Gibson and Ashby ${ }^{19)}$ proposed.

$$
E=E_{\text {true }} \times(1-\varepsilon)^{2} .
$$

Here, $E_{\text {true }}$ is true elastic modulus. Matrix was assumed to be composed of an active component, and true elastic modulus of the matrix was to be $24 \mathrm{GPa}$ on the basis of the measurement of elastic modulus for coke matrix with the Nanoindentation method. ${ }^{20)}$ Meanwhile, the elastic modulus of pore was to be $10^{-4}$ times smaller than that of matrix. $\varepsilon$ is strain and described by Eq. (16):

$$
\varepsilon_{i j}=\frac{1}{2}\left(\frac{\partial u_{i}}{\partial x_{j}}+\frac{\partial u_{j}}{\partial x_{i}}\right) .
$$

Here, $u$ is displacement. The algebraic multi-grid solvers, $\mathrm{AMGS}^{21)}$ were used for solution of system of equations.

\section{Results and Discussion}

\subsection{Effect of Reaction Temperature on Conversion Dis- tribution in the Coke Lump}

Figure 3 shows conversion distributions in the coke lump with whole (average) conversion of $0.1,0.2$, and 0.3 at reaction temperature of 1273,1473 , and $1673 \mathrm{~K}$. At reaction temperature of 1273 or $1473 \mathrm{~K}$, the conversion of coke matrices gradually decreased from the Dirichlet boundary of mass fraction $(z=5 \mathrm{~mm})$ to the inside one $(z=0 \mathrm{~mm})$ with an increase in whole conversion, suggesting that $\mathrm{CO}_{2}$ gasification reaction relatively progressed uniformly in the coke lump at lower reaction temperature. In contrast, at reaction temperature of $1673 \mathrm{~K}$, the conversion is higher near the Dirichlet boundary than inside, and the coke matrices in which reaction progress little are found to exist. To quantitatively evaluate reaction degree of coke matrices, changes in reaction rate averaged over the crosssectional area for progress in reaction in the $z$-direction of the coke lump indicated in Fig. 4 are discussed. At reaction temperature of $1273 \mathrm{~K}$, the reaction rate showed almost the same value in the whole coke lump regardless of degree in the progress of the reaction, suggesting that reaction uniformly progressed. At reaction temperature of $1473 \mathrm{~K}$, although reaction rate is almost the same in a coke lump as is the same in $1273 \mathrm{~K}$, the reaction rate is larger at $1473 \mathrm{~K}$ than at $1273 \mathrm{~K}$. This would be because reaction progresses more with an increase in reaction temperature. On the other hand, at reaction temperature of $1673 \mathrm{~K}$, the reaction rate is almost zero in the deepest inside while it is high at the Dirichlet boundary $(z=5 \mathrm{~mm})$ with the entire conversion of 0.1 , indicating that the reaction progressed mainly in the vicinity of the Dirichlet boundary. Further, the distribution of reaction rate did not change much in the deepest inside even with the entire conversion of 0.2 and 0.3 . These trends are consistent with the results obtained by the conversion distributions. These facts show that the rate-controlling step changed according to reaction temperature because the coke lump reacted uniformly at reaction temperature of 1273 or $1473 \mathrm{~K}$ and did mainly near the Dirichlet boundary at 1673 $\mathrm{K}$. Kawakami et al. ${ }^{22)}$ performed the experiment of $\mathrm{CO}_{2}$ gasification reaction for a spherical coke sample with diameter of about $20 \mathrm{~mm}$ and reported that the reaction progressed 


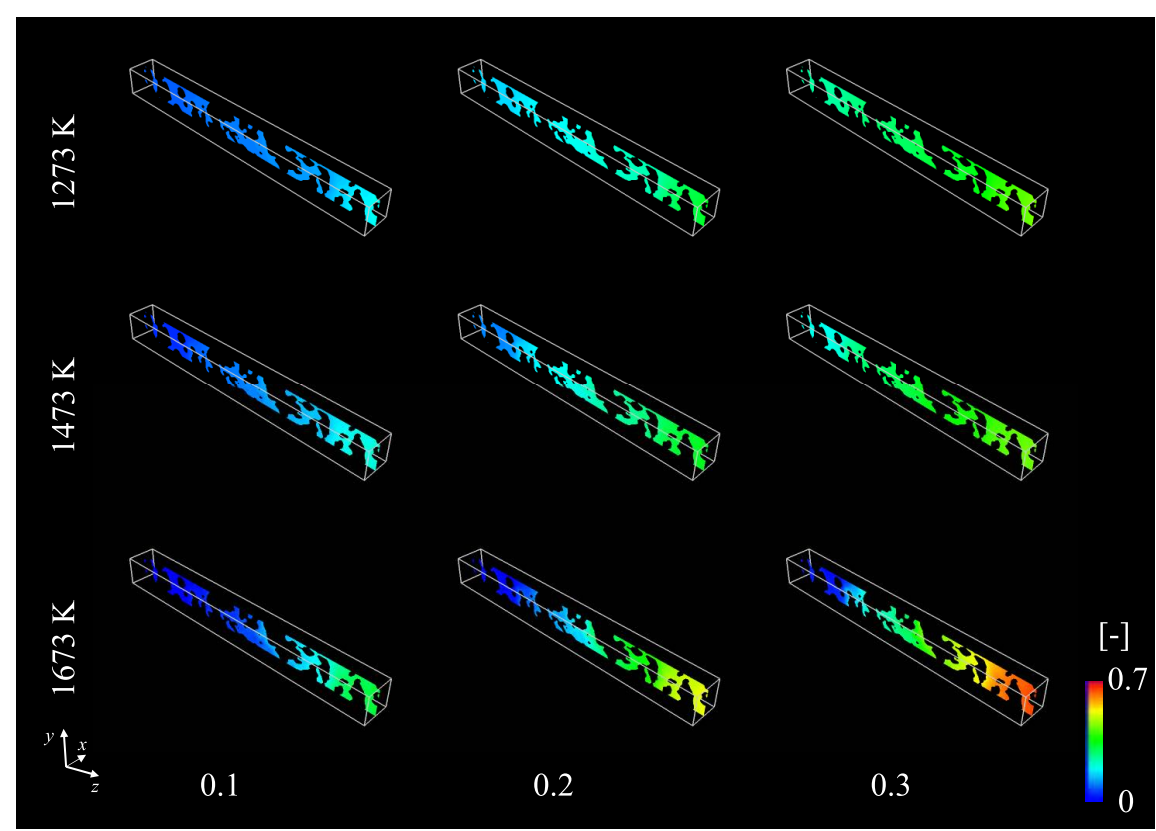

Fig. 3. Distributions of conversion at $x=0.25 \mathrm{~mm}$. The reaction temperatures were set at (top) $1273 \mathrm{~K}$, (middle) $1373 \mathrm{~K}$, and (bottom) $1473 \mathrm{~K}$. The total conversions are (left) 0.1 , (center) 0.2 , and (right) 0.3 . (Online version in color.)

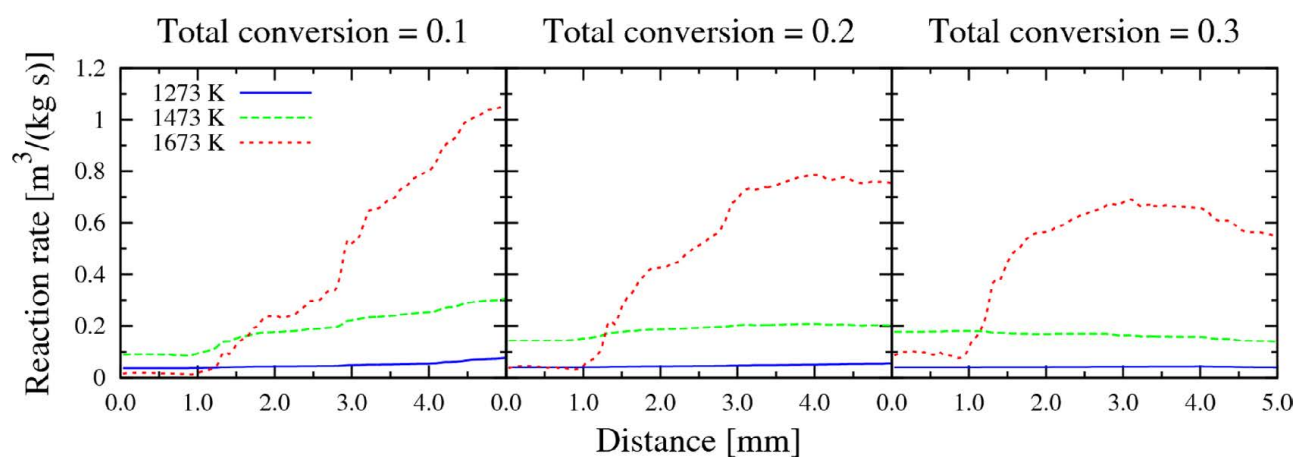

Fig. 4. Distributions of cross-sectional mean reaction rate along the $z$-axis. (Online version in color.)

in the whole of the sample at reaction temperature of below $1273 \mathrm{~K}$, at reaction temperature of above $1373 \mathrm{~K}$ the reaction layer formed only in the vicinity of the sample surface, and the unreacted core remained in the sample center. These results indicate the rate-controlling step shifts from volumetric to external surface reaction with an increase in reaction temperature. Therefore, our results also reproduce their experimental results in which the rate-controlling step changes would be reasonable. Although the rate-controlling step changed at reaction temperature of 1473-1673 K, it did at $1373 \mathrm{~K}$ in the experiment of Kawakami et al. However, it would be difficult to compare them exactly because there are discrepancies in coal type and sample diameter in the experiment of Kawakami et al. and our study.

\subsection{Effect of Reaction Temperature on $\mathrm{CO}_{2}$ Gas Con- centration in the Coke Lump}

As is shown in the distribution of $\mathrm{CO}_{2}$ gas concentration in Fig. 5, a longer time is required for $\mathrm{CO}_{2}$ gas to diffuse inside coke for higher reaction temperature conditions. This is because reaction rate of coke matrices are large and $\mathrm{CO}_{2}$ is consumed before it diffuses inside coke in case of higher temperatures. Also, the volume fraction of $\mathrm{CO}_{2}$ gas increased along with progress in the reaction of all the reac- tion temperatures. Thus, $\mathrm{CO}_{2}$ is found to diffuse inside the coke lump along with progress in reaction. This is because the porosity near the Dirichlet boundary of concentration became higher and the diffusive velocity of $\mathrm{CO}_{2}$ gas in coke matrix and pores increased.

\subsection{Evaluation of Rate-controlling Steps Using the Thiele Modulus}

Figure 6 indicates the distributions of $\mathrm{CO}_{2}$ concentration at 1273,1473 , and $1673 \mathrm{~K}$ for the radial direction obtained by our numerical analysis and their fitting-curves using the Thiele modulus. Tables $\mathbf{3}$ and $\mathbf{4}$ summarize the Thiele modulus and the effectiveness factors of catalyst obtained by curve-fitting, respectively. The Thiele modulus increased and the effectiveness factor of catalyst decreased with elevated temperature, suggesting that gas diffusion was rate-controlling step for higher reaction temperature. Furthermore, the Thiele modulus decreased and the effectiveness factor of catalyst increased along with progress in reaction regardless of reaction temperature, suggesting that rate-controlling step shits from gas diffusion to chemical reaction along with progress in reaction. These trends correspond to conversion distributions in the coke lump discussed above, and the Thiele modulus can evaluate rate-controlling 


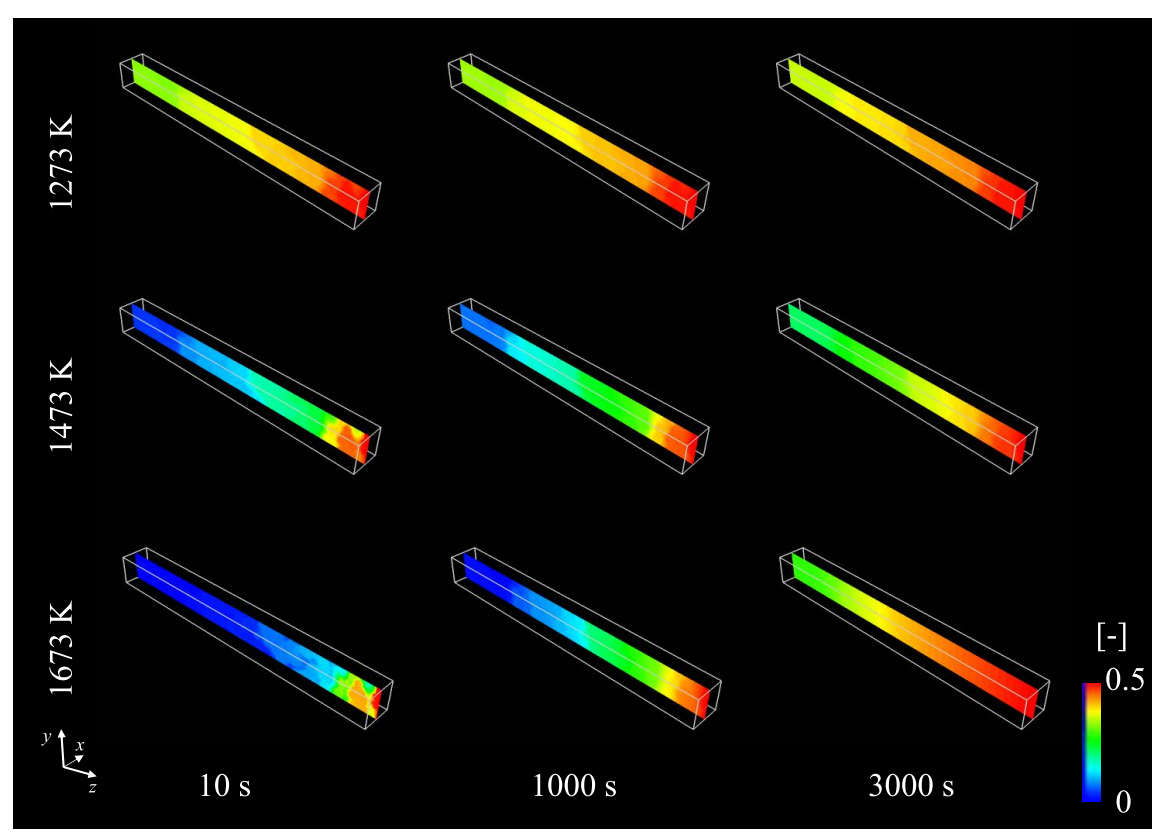

Fig. 5. Distributions of $\mathrm{CO}_{2}$ volume fraction at $x=0.25 \mathrm{~mm}$. The reaction temperatures were set at (top) $1273 \mathrm{~K}$, (middle) $1373 \mathrm{~K}$, and (bottom) $1473 \mathrm{~K}$. The total conversions are (left) 0.1, (center) 0.2, and (right) 0.3. (Online version in color.)

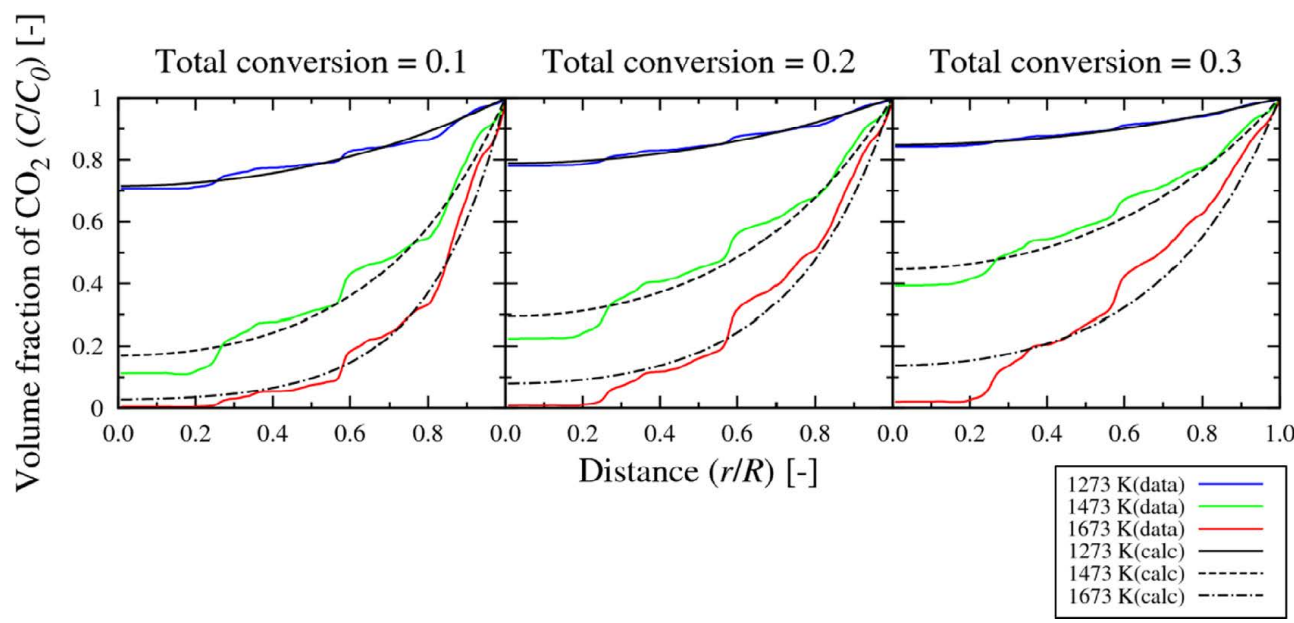

Fig. 6. Distribution of cross-sectional mean $\mathrm{CO}_{2}$ volume fraction along the $z$-axis. The "data" in graphs was calculated by the finite element method, and the "calc" was calculated by Eq. (11). (Online version in color.)

Table 3. Thiele modulus.

\begin{tabular}{clll}
\hline Conversion & 0.1 & 0.2 & 0.3 \\
\hline $1273 \mathrm{~K}$ & 0.488 & 0.407 & 0.336 \\
$1473 \mathrm{~K}$ & 1.27 & 1.01 & 0.791 \\
$1673 \mathrm{~K}$ & 2.02 & 1.60 & 1.36 \\
\hline
\end{tabular}

step in the coke lump. Moreover, focusing on curve-fitting accuracy, the accuracy is lower with reaction temperature of 1473 or $1673 \mathrm{~K}$ than with that of $1273 \mathrm{~K}$. This is because $\mathrm{CO}_{2}$ concentration drastically changed in case of high reaction temperature, and the pore structure in the coke lump would affect curve-fitting accuracy. This trend is more remarkable with higher reaction temperature conditions.

\subsection{Effect of Reaction on Stress State Inside a Coke Lump}

Stress analysis was performed for coke structure with the
Table 4. Effectiveness factor.

\begin{tabular}{clll}
\hline Conversion & 0.1 & 0.2 & 0.3 \\
\hline $1273 \mathrm{~K}$ & 0.881 & 0.913 & 0.938 \\
$1473 \mathrm{~K}$ & 0.582 & 0.669 & 0.754 \\
$1673 \mathrm{~K}$ & 0.413 & 0.495 & 0.555 \\
\hline
\end{tabular}

entire conversion of $0.1,0.2$ or 0.3 with reaction temperature of 1273,1473 , and $1673 \mathrm{~K}$ and the obtained stress distributions are shown in Fig. 7. Regardless of reaction temperature, stress showed on matrices decreased with an increase in the entire conversion. This is caused by an increase in porosity of matrix element and a decrease in elastic modulus along with progress in reaction. Therefore, a decrease in stress on matrices corresponds to a decrease in coke strength. Further, since the reaction progressed in the whole of the sample at reaction temperature of 1273 or $1473 \mathrm{~K}$, stress decreased uniformly in the coke lump. In contrast, 


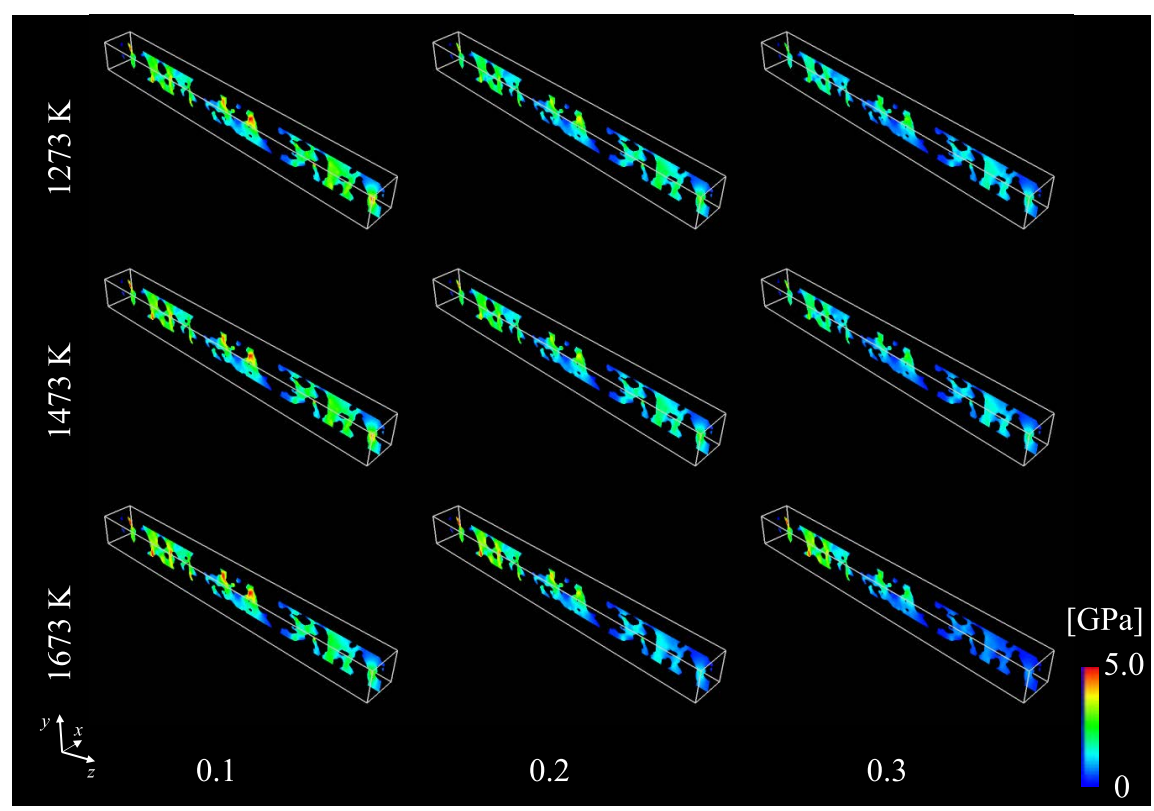

Fig. 7. Distribution of von Mises stress at $x=0.25 \mathrm{~mm}$. The reaction temperatures were set at (top) $1273 \mathrm{~K}$, (middle) 1373 $\mathrm{K}$, and (bottom) $1473 \mathrm{~K}$. The total conversions are (left) 0.1 , (center) 0.2 , and (right) 0.3 . (Online version in color.)

since the reaction progressed selectively near the Dirichlet boundary of concentration at $1673 \mathrm{~K}$, stress decreased only in the vicinity of the boundary. Consequently, coke strength decreases near the external surface when the reaction temperature is high, whereas it does uniformly in the whole of a coke lump when the reaction temperature is low.

\section{Conclusions}

In this study, we developed the coke model considering coke pore structure and investigated its degradation behavior with progress in $\mathrm{CO}_{2}$ gasification reaction according to the reaction condition in the blast furnace using the finite element method. Specifically, the actual coke was imaged using the X-ray CT (computed tomography), and the coke model was developed on the basis of the image-based modeling with the CT images. Then, gas diffusion in a coke lump and reaction of coke matrix were numerically analyzed using the finite element method. As a result, the reaction progressed in the vicinity of the external surface of the coke lump at reaction temperature of $1673 \mathrm{~K}$, whereas the reaction progressed uniformly inside the coke lump at below $1473 \mathrm{~K}$, indicating a change in the rate-controlling step according to reaction temperature successfully. Further, the Thiele modulus increased and the effectiveness factor of catalyst decreased with an increase in reaction temperature. Since this trend is consistent with conversion distribution in the coke lump, the Thiele modulus would have the capability to evaluate the rate-controlling step of the reaction in a coke lump. In addition, the stress analysis for the coke model after reaction predicted a decrease in coke strength near the external surface of the coke lump because the reaction progressed near the surface in case of diffusion-controlling step while it described a decrease in coke strength in the whole coke lump in case of the reaction-controlling step.

\section{Acknowledgement}

This work was carried out as a part of the research activities " $\mathrm{CO}_{2}$ Ultimate Reduction in Steelmaking process by Innovative technology for cool Earth 50 (COURSE50). The financial support from New Energy and Industrial Technology Development Organization (NEDO) is gratefully acknowledged.

\section{REFERENCES}

1) Y. Saito, S. Matsuo, Y. Matsushita and H. Aoki: J. Jpn. Inst. Energy, 95 (2016), 563.

2) Y. Kubota and K. Uebo: J. Jpn. Inst. Energy, 95 (2016), 548.

3) J. W. Patrick and A. E. Stacey: Fuel, 51 (1972), 81.

4) I. Shimoyama: Tetsu-to-Hagané, 96 (2010), 209.

5) T. Nishi, H. Haraguchi and T. Okuhara: Tetsu-to-Hagané, 73 (1987), 1869.

6) M. Kawakami, K. Murayama, M. Shibata, T. Takenaka and H. Toda: Tetsu-to-Hagané, 87 (2001), 252.

7) T. Kamijo, H. Iwakiri, J. Kiguchi, T. Yabata, H. Tanaka and M. Kitamura: Tetsu-to-Hagané, 73 (1987), 2012.

8) H. Hayashizaki, K. Ueoka, M. Kajiyama, Y. Yamazaki, K. Hiraki, Y. Matsushita, H. Aoki, T. Miura, K. Fukuda and K. Matsudaira: Tetsu-to-Hagané, 95 (2009), 593

9) K. Hiraki, Y. Yamazaki, T. Kanai, A. Uchida, Y. Saito, Y. Matsushita, H. Aoki, T. Miura, S. Nomura and H. Hayashizaki: ISIJ Int., 52 (2012), 1966.

10) N. Tsafnat, N. Amanat and A. S. Jones: Fuel, 90 (2011), 384.

11) H. Lomas, D. R. Jenkins, M. R. Mahoney, R. Pearce, R. Roest, K. Steel and S. Mayo: Fuel Process. Technol., 155 (2017), 183.

12) N. Otsu: IEEE Trans. Syst. Man Cybern., 9 (1979), 62.

13) D. E. Rosner and P. Tandon: AIChE J., 40 (1994), 1167.

14) Y. Kashiwaya and K. Ishii: ISIJ Int., 31 (1991), 440.

15) Y. Notay: AGMG software and documentation, http://homepages.ulb. ac.be/ ynotay/AGMG/, (accessed 2018-02-25).

16) Y. Notay: SIAM J. Sci. Comput., 34 (2012), A2288.

17) Y. Notay and A. Napov: SIAM J. Sci. Comput., 34 (2012), A1079.

18) Y. Notay: Electron. Trans. Numer. Anal., 37 (2010), 123.

19) R. C. Giberson and J. P. Walker: Carbon, 3 (1966), 521.

20) M. Mihashi, M. Soejima, Y. Asakuma, T. Yamamoto, H. Aoki, T. Miura, K. Kato and S. Itagaki: Tetsu-to-Hagané, 88 (2002), 188.

21) H. P. C. Laboratory: AMGS, http://hpcl.info.kogakuin.ac.jp/lab/ software/amgs, (accessed 2018-02-25).

22) M. Kawakami, K. Murayama, M. Shibata, T. Takenaka and H. Toda: Tetsu-to-Hagané, 87 (2001), 252. 